\title{
STUDI EKSPERIMENTAL KONDENSOR PIPA KONSENTRIK
}

\author{
Sartono Putro \\ Jurusan Teknik Mesin Fakultas Teknik \\ Universitas Muhammadiyah Surakarta \\ Jl. A. Yani Kotak Pos 1 Pabelan Surakarta \\ email: sartono_putro@ums.ac.id
}

\begin{abstract}
ABSTRAK
Kondensor merupakan salah satu alat utama dalam proses pembuatan minyak atsiri. Penggunaan kondensor yang masih sederhana dalam pengolahan minyak atsiri oleh para petani minyak atsiri, mendorong untuk dilakukan penelitian ini. Kegiatan meliputi perancangan dan pengujian model kondensor untuk mengetahui kapasitas kondensat, daya pompa, dan koefisien perpindahan kalor menyeluruh dengan variasi Bilangan Reynold fluida dingin.

Jenis kondensor yang digunakan dalam penelitian ini adalah kondensor pipa konsentrik dengan aliran fluida berlawanan arah. Fluida dingin mengalir pada sisi shell dan fluida panas mengalir pada sisi tube. Bahan shell dari mild steel dengan dimensi: diameter luar 50,6 mm, diameter dalam 49,7 mm, dengan panjang 1500 $\mathrm{mm}$. Adapun bahan tube dari tembaga dengan diameter luar 25,7 $\mathrm{mm}$ sedangkan diameter dalamnya 23,6 mm dengan panjang tube $1700 \mathrm{~mm}$. Adapun jumlah kondensor yang digunakan dua buah dipasang secara seri atas bawah. Data-data yang diambil adalah temperatur masuk dan keluar fluida dingin, temperatur masuk fluida panas, kapasitas kondensat dan beda tekanan masuk dan keluar fluida dingin.

Hasil yang diperoleh pada penelitian ini adalah dengan meningkatnya bilangan Reynold, maka kapasitas kondensat, daya pompa serta koefisien perpindahan kalor menyeluruhnya mengalami peningkatan. Pada bilangan Reynold 2000, 4000, 6000, 8000 dan 10000, diperoleh kapasitas kondensat sebesar 0,00148; 0,00179; 0,00204; 0,00246; $0,00262 \mathrm{~kg} / \mathrm{s}$, besarnya daya pompa 0,129; 0,256; 0,401; 0,597; 0,836 W, dan koefisien perpindahan kalor menyeluruhnya 21,090; 28,867; 30,832; 35,811; 37,793 W/m² K.
\end{abstract}

Kata Kunci: kondensor, pipa konsentrik, aliran berlawanan, bilangan Reynold, kondensat.

\section{PENDAHULUAN}

Kondensor merupakan salah satu alat utama dalam proses pembuatan minyak atsiri. Saat ini banyak petani minyak atsiri yang melakukan proses produksinya dengan peralatan yang sangat sederhana utamanya dalam penggunaan kondensor. Laksamanahardja dkk. (2003), menjelas- kan bahwa minyak atsiri banyak digunakan dalam industri obat-obatan, flavor, fragrance dan parfum. Indonesia telah mengekspor 14 jenis minyak atsiri, ini berarti terdapat peluang besarbagi petani untuk berperan dalam agro industri minyak atsiri. Selain mengekspor, Indonesia juga mengimporbeberapa jenis minyak atsiri dalam jumlah yang 
besar. Pada tahun 1998, ekspor minyak atsiri tercatat 27,30 ton dengan nilai 120,26 juta dolar Amerika, sedangkan im-pornya 54,32 ton dengan nilai 200,13 juta dolar Amerika. Data ini menunjukkan bahwa peluang untuk mengembangkan agro industri minyak atsiri cukup besar karena penggunaan turunan minyak atsiri pada berbagai industri dalam negeri juga besar.

Masih menurut Laksamanahardja dkk. (2003), impor minyak atsiri Indonesia yang masih tinggi antara lain disebabkan teknologi pengolahan minyak atsiri di Indonesia belum mampu mengikuti perkembangan teknologi di negara lain yang telah maju pesat. Umumnya petani minyak atsiri masih menerapkan teknologi yang bersifat tradisional sehingga kontinuitas pengadaan dan konsistenan mutu yang tidak terjamin.

Penggunaan peralatan penyulingan yang sederhana masih diterapkan para petani minyak atsiri di daerah Musuk, Boyolali. Kondensoryang digunakan berupa kolam besar berukuran $9 \times 3 \times 2,5$ meter yang didalamnya ditempatkan pipa berdiameter 2 inchi yang dipasang zig-zag dengan panjang mencapai 72 meter. Kondensor jenis ini tidak memenuhi kriteria heat exchanger, sehingga menarik untuk dilakukan rancang bangun model kondensor yang sesuai dengan teori heat exchanger agar dapat menghasilkan kapasitas kondensat yang tinggi.

\section{TINJAUAN PUSTAKA}

Sukirno (2004), meneliti variasi panjang alat penukar kalor terhadap performa alat penukar kalor pipa konsentrik aliran searah dan berlawanan. Variasi panjang pipa yaitu $1 \mathrm{~m}, 2 \mathrm{~m}$, dan $3 \mathrm{~m}$, untuk fluida panas menggunakan minyak oli SAE 20W-50 yang berada di luar pipa dan fluida dingin menggunakan air yang berada di dalam pipa. Hasil penelitiannya menunjukkan bahwa semakin panjang pipa alat penukar kalor akan mengakibatkan rugi panas yang semakin besar. Rugi panas yang terjadi dengan panjang $1 \mathrm{~m}$ untuk aliran searah lebih besar dibanding dengan aliran yang berlawanan. Hal ini karena aliran berlawanan memiliki dimensi alat penukar kalor lebih pendek dibanding dengan alat penukar kalor aliran searah.
Sedangkan Ardani (2004), telah melakukan penelitian mengenai pengaruh temperatur masukan oli terhadap performa alat penukar kalor tipe shell and tube. Variasi temperatur adalah $60{ }^{\circ} \mathrm{C}, 70^{\circ} \mathrm{C}$ dan $80{ }^{\circ} \mathrm{C}$, dengan jarak sekat $36 \mathrm{~mm}$, debit 1500 1/jam. Hasil yang diperoleh dari penelitiannya adalah temperatur masukan yang tinggi menyebabkan nilai koefisien perpindahan panas akan semakin turun. Adapun pressure drop sisi shell terlihat bahwa semakin tinggi temperatur masukan oli maka pressure drop dari shell akan semakin turun, hal ini diakibatkan perubahan propertis dari fluida akibat temperatur terutama harga viskositas dan densitas oli. Untuk temperatur semakin tinggi harga viskositas fluida semakin turun, dan densitas oli juga semakin kecil.

Sementara itu Evanudin (2005), melakukan penelitian dengan variasi potongan sekat horisontal 20\%, 40\% dan 50\% untuk aliran searah pada alat penukar kalor tipe shell and tube satu lintasan dengan jarak antar sekat konstan $36 \mathrm{~mm}$. Hasil penelitian menunjukkan bahwa semakin besar pemotongan sekat, maka pressure drop sisi shell akan semakin kecil. Pemotongan sekat yang semakin besar juga menyebabkan koefisien perpindahan panas menyeluruh semakin menurun. Penurunan koefisien perpindahan panas menyeluruh pada sisi shell terjadi karena pada pemotongan sekat yang lebih besar maka aliran by pass yang terjadi akan semakin besar, pemotongan sekat yang semakin besar juga akan menurunkan jumlah fraksi tube.

Handoyo (2000), dalam penelitian tentang pengaruh kecepatan aliran terhadap efektivitas suatu shell and tube dengan udara sebagai fluida kerja didapatkan hasil bahwa efektivitas naik seiring dengan kenaikan kecepatan hingga suatu harga tertentu dan kemudian akan turun. Efektivitas shell and tube heat exchanger lebih tinggi jika udara panas mengalir dengan kecepatan tinggi di sisi tube dan udara dingin mengalir dengan kecepatan rendah di sisi shell. Hal ini disebabkan gas memiliki kerapatan lebih rendah dibanding cairan. Demikian pula udara panas memiliki kerapatan lebih rendah dibanding udara dingin, karena kerapatan udara panas lebih 
rendah maka agar koefisien perpindahan panas konveksinya tinggi sedang luasan tidak diperbesar, udara panas harus mengalir dengan kecepatan tinggi di sisi tube.

\section{Landasan Teori}

Sesuai hukum kesetimbangan panas, maka panas yang masuk sama dengan panas yang dilepaskan. Persamaannya dapat ditulis sebagai berikut.

$q_{c}=q_{h}$

$\dot{m}_{c} \times C p_{c} \times\left(T_{c, o}-T_{c, i}\right)=\dot{m}_{h} \times C p_{h} \times\left(T_{h, i}-T_{h, o}\right)$

$q=$ Kalor yang dipindahkan(Watt)

$C_{p}=$ Panas jenis $(\mathrm{J} / \mathrm{kgK})$

$\dot{m}=$ Laju aliran massa $(\mathrm{kg} / \mathrm{s})$

$T=$ Temperatur (K).

${ }_{c, h}=$ Fluida dingin, fluida panas

${ }_{i, o}^{c, h}=$ Masuk, keluar

Persamaan laju perpindahan panas dengan metode LMTD (log mean temperature diference) sebagai berikut (Incropera, 1996):

$q=U \cdot A \cdot \Delta T_{L M T D}$

dengan:

$q=$ Kalor yang dipindahkan (Watt).

$U=$ Koefisien perpindahan kalor menyeluruh $\left(\mathrm{W} / \mathrm{m}^{2} \mathrm{~K}\right)$.

$A=$ Luas permukaan perpindahan kalor $\left(\mathrm{m}^{2}\right)$.

$D T_{L M T D}=$ Beda temperatur rata-rata $(\mathrm{K})$

Beda temperatur rata-rata parallel flow:

$$
\Delta T_{L M T D}=\frac{\left(T_{h o}-T_{c o}\right)-\left(T_{h i}-T_{c i}\right)}{\ln \left(T_{h o}-T_{c o}\right) /\left(T_{h i}-T_{c i}\right)}
$$

counter flow:

$\Delta T_{L M T D}=\frac{\left(T_{h o}-T_{c i}\right)-\left(T_{h i}-T_{c o}\right)}{\ln \left(T_{h o}-T_{c i}\right) /\left(T_{h i}-T_{c o}\right)}$

Apabila temperatur fluida masuk dan keluar belum diketahui, harus dilakukan prosedur iterasi. Untuk menghindari kelamaan dalam penghitungan, digunakan metode yang lebih mudah yaitu dengan metode yang berdasarkan atas efektivitas penukar kalor. Efektivitas suatu penukar kalor didefinisikan sebagai berikut (Incropera, 1996):

$$
\begin{aligned}
& \varepsilon=\frac{q}{q_{\max }} \\
& \varepsilon=\text { Efektivitas } \\
& q_{\max }=\text { Kalor maksimum yang dipindahkan } \\
& \text { (Watt). }
\end{aligned}
$$

Fluidayang memilikibeda suhumaksimum adalah fluida yang memiliki nilai laju aliran massa minimum, hal ini disebabkan energi yang di terima fluida yang satu mesti sama dengan energi yang dilepas oleh fluida yang satu lagi, sehingga persamaan untuk perpindahan panas maksimum diperoleh:

$q_{\max }=C_{\min } \cdot\left(T_{h i}-T_{c i}\right)$

$C_{\min }=C_{c}=C_{h}$, apabila: $C_{c}<C_{h}$, maka

$q_{\max }=C_{c}\left(T_{h, i}-T_{c, i}\right)$. Apabila $C_{h}<C_{c}$

$q_{\max }=C_{h}\left(T_{h, i}-T_{c, i}\right)$

$C=$ heat capacity rate

NTU-Efektifitas dapat ditentukan dengan persamaan sebagai berikut: (Incropera, 1996).

$N T U=\frac{U \cdot A}{C_{\min }}$

$N T U=$ Jumlah satuan perpindahan

Untuk silinder berlubang yang terkena lingkungan konveksi pada permukaan, luas bidang tergantung dari diameter dalam pipa dan tebal dinding.

Koefisien perpindahan panas menyeluruh untuk bagian dalam tube ( ) dan bagian luar tube $\left(U_{o}\right)$ adalah (Incropera, 1996).

$U_{o}=$

$\frac{1}{\frac{1}{h_{o}}+R_{f, o}+\frac{r_{o}}{k} \ln \left(\frac{r_{o}}{r_{i}}\right)+\left(\frac{r_{o}}{r_{i}}\right) R_{f, i}+\left(\frac{r_{o}}{r_{i}}\right) \frac{1}{h_{i}}}$. 
$h=$ Koefisien perpindahan kalor konveksi fluida $\left(\mathrm{W} / \mathrm{m}^{2} \mathrm{~K}\right)$.

$k=$ Koefisien perpindahan kalor konduksi tube $\left(\mathrm{W} / \mathrm{m}^{2} \mathrm{~K}\right)$.

$r_{o}=$ Jari-jari luar tube $(\mathrm{m})$

$r_{i} \quad=$ Jari-jari dalam tube $(\mathrm{m})$

$R_{f_{0}}=$ faktor kotoran di luar tube $\left(\mathrm{m}^{2} \mathrm{~K} / \mathrm{m}\right)$

$R_{f i}=$ faktor kotoran di dalam tube $\left(\mathrm{m}^{2} \mathrm{~K} / \mathrm{m}\right)$

Untuk menentukan nilai koefisien perpindahan panas konveksi sangat rumit karena nilai koefisien perpindahan panas konveksi dalam sebuah sistem tergantung pada geometri permukaan dan sifat-sifat termal fluida (konduktivitas termal, kalor spesifik, densitas). Bilangan $\operatorname{Nusselt}(\mathrm{Nu})$ merupakan ukuran untuk menentukan koefisien perpindahan panas konveksi dengan lebih mudah.

$D=$ Diameter tube $(\mathrm{m})$

Nilai Bilangan Nusselt untuk aliran turbulen dalam tube berkembang penuh diberikan oleh Dittus dan Boelter (Incropera, 1996).

$$
\begin{aligned}
N u= & 0,023 \times \operatorname{Re}^{4 / 5} \times \operatorname{Pr}^{n} \ldots \ldots \ldots \ldots \ldots \ldots . . .(10) \\
\operatorname{Re}= & \text { Bilangan Reynold } \\
\operatorname{Pr}= & \text { Bilangan Prandt } \\
\mathrm{n}= & 0,3 \text { untuk pendinginan }=0,4 \text { untuk } \\
& \text { pemanasan }
\end{aligned}
$$

Sedangkan untuk aliran laminer di dalam tube dirumuskan sebagai berikut (Sieder dan Tate dalam Holman, 1997):

$$
\begin{aligned}
N u= & 1,86 \cdot\left(\operatorname{Re}_{d} \cdot \operatorname{Pr}\right)^{1 / 3} \cdot\left(\frac{D}{L}\right)^{1 / 3} \cdot\left(\frac{\mu}{\mu_{w}}\right)^{0,14} \ldots . .(11) \\
\mu & =\text { Viskositas dimanik }(\mathrm{kg} / \mathrm{ms}) \\
& =\text { Viskositas dimanik dinding }(\mathrm{kg} / \mathrm{ms}) \\
L \quad & =\text { Panjang tube }(\mathrm{m})
\end{aligned}
$$

\section{METODE PENELITIAN}

Bahan yang digunakan dalam penelitian adalah:

1. Fluida pendingin yang mengalir dalam kondensor adalah dengan air yang langsung diambil dari sumber air.

2. Fluida panas yang digunakan adalah hasil penguapan air yang dipanaskan dalam bejana.

Adapun peralatan yang digunakan dalam penelitian merupakan model kondensor pipa konsentrik dari baja karbon untuk bagian shel dan tembaga untuk tube.

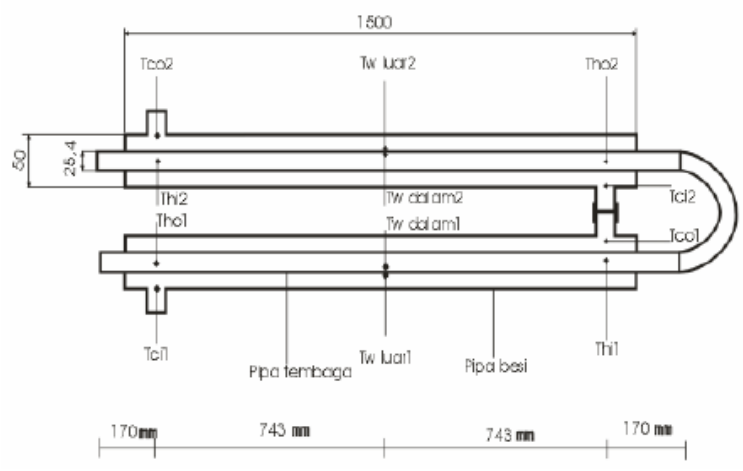

\section{Gambar 1. Skema Alat Uji}

Fluida dingin (air) dialirkan pada bagian shell kondensor yang mengalir dari bawah(Tci,1) menuju ke atas hingga sampai keluar (Tco,2). Sedangkan fluida panasnya mengalir pada bagian tube dari atas (Thi,2) hingga keluar ke bawah (Tho,1).

Prosedur pengambilan data:

1. Menyalakan kompor hingga air dalam bejana mendidih.

2. Mengalirkan fluida dingin dengan pompa air.

3. Mengatur aliran fluida dengan melihat skala pada flow meter. Aliran diatur dengan memutar keran hingga sesuai dengan aliran yang diharapkan.

4. Pengambilan data dilakukan setelah adanya aliran kondensat yang konstan.

5. Pengambilan data meliputi:

a. Temperatur air masuk (Tci)

b. Temperatur air keluar (Tco)

c. Temperatur uap masuk kondensor (Thi) 


\section{Gambar 2. Diagram Alir Penelitian}

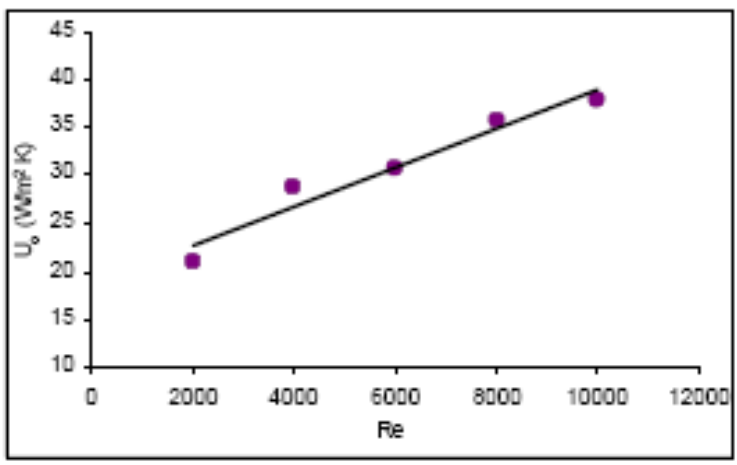

ansor

( )

ut fluida

gan variasi Igin 2000,

Pengukuran dan perhitungan pengaruh Bilangan Reynold fluida dingin terhadap: 1. Kapasitas kondensat

2. Koefisien perpindahan kalor total 3. Daya pompa

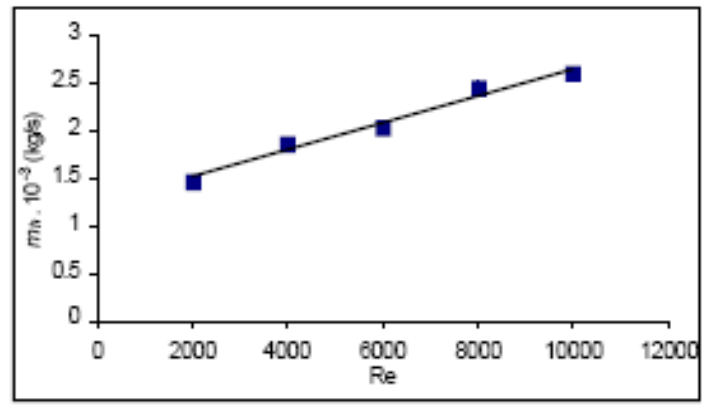

\section{Gambar 3. Hubungan Kapasitas Kondensat dengan Bilangan Reynolds (Re) Fluida Dingin}

Gambar 4 memperlihatkan kenaikan Bilangan Reynold fluida dingin meningkatkan koefisien perpindahan kalor menyeluruh. Hal ini mendukung penjelasan sebelumnya bahwa peningkatan Bilangan Reynold fluida dingin dapat meningkatkan kapsitas kondensat. Data penelitian menunjukkan besarnya koefisien perpindahan kalor menyeluruh adalah adalah 21,090 W/ $\mathrm{m}^{2} \mathrm{~K}, 28,859 \mathrm{~W} / \mathrm{m}^{2} \mathrm{~K}, 30,832 \mathrm{~W} / \mathrm{m}^{2} \mathrm{~K}, 35,812$ $\mathrm{W} / \mathrm{m}^{2} \mathrm{~K}, 37,794 \mathrm{~W} / \mathrm{m}^{2} \mathrm{~K}$. Hasil ini berbanding lurus dengan Bilangan Reynolds fluida dingin.

\section{Gambar 4. Hubungan Koefisien}

\section{Perpindahan Kalor Menyeluruh dengan} Bilangan Reynolds (Re) Fluida Dingin

Meningkatnya Bilangan Reynold fluida dingin juga meningkatkan jumlah kalor yang dilepas ke lingkungan. Dengan tidak diisolasinya permukaan dinding luar shell, maka dapat mempermudah pelepasan kalor fluida dingin ke lingkungan. Kondisi ini menguntungkan untuk operasi kondensor. Hasil pengolahan data eksperimen, menunjukkan kalor yang terbuang 
untuk Bilangan Reynolds dari yang kecil hingga besar berturut-turut adalah 3,396 kW, 4,206 $\mathrm{kW}, 4,565 \mathrm{~kW}, 5,457 \mathrm{~kW}$, dan 5,6343 kW.

\section{Gambar 5. Pengaruh Bilangan Reynolds (Re) Fluida Dingin Dengan Kalor yang Dilepas ke Lingkungan}

Kapasitas kondensat juga dipengaruhi temperatur masuk fluida dingin. Penelitian ini menggunakan fluida dengin dengan temperatur aliran masuk tidak konstan. Gambar 6 menunjukkan bahwa semakin tinggi temperatur masuk fluida dingin maka kapasitas kondensat semakin menurun. Kemampuan air menyerap kalor adalah perkalian kalor jenis dan selisih temperatur sesuai laju aliran massa. Propertis air dalam hal ini kalor jenis $(\mathrm{Cp})$ nilainya menurun dengan meningkatnya temperatur. Namun demikian untuk Bilangan Reynold pada aliran turbulen, pengaruh perubahan temperatur masuk fluida dingin tidak signifikan.

\section{Gambar 6. Pengaruh Temperatur Masuk Fluida Dingin dengan Kapasitas Kondensat untuk Bilangan Reynold Fluida Dingin 2000}

\section{Gambar 7. Pengaruh Kapasitas Kondensat terhadap Daya Pompa}

Kenaikan Bilangan Reynold fluida dingin yang dapat meningkatkan kapasitas kondensat, juga memiliki implikasi kenaikan daya pompa. Hal ini dapat dimengerti karena naiknya Bilangan Reynold berarti debit aliran juga naik sehingga kebutuhan daya pompa juga naik.

Gambar 8 menjelaskan hubungan Bilangan Reynold fluida dingin dengan kapasitas kondensat dan daya pompa. Kenaikan kapasitas kondensat dapat dikatakan linier, sedangkan kenaikan daya pompa mendekati fungsi kuadrat. Optimasi operasional kondensor untuk pembuatan minyak atsiri harus dihitung harga minyak atsiri dengan biaya listrik penggerak pompa.

\section{KESIMPULAN}

Berdasarkan pengolahan data yang telah diuraikan sebelumnya, dapat ditarik suatu kesimpulan sebagai berikut :

1. Semakin meningkatnya bilangan Reynolds fluida dingin maka kapasitas kondensat mengalami peningkatan. Hal ini karena debit aliran fluida yang terjadi semakin besar, sehingga proses pertukaran kalor antara fluida panas dan fluida dingin lebih cepat terjadi. Dari hasil penelitian, untuk Bilangan Reynolds 2000, kapasitas kondensatnya $1,480610^{-3} \mathrm{~kg} / \mathrm{s}$. Sedangkan untuk bilangan Reynolds 10000, kapasitas kondensatnya $2,6168 \times 10^{-3} \mathrm{~kg} / \mathrm{s}$.

2. Dengan meningkatnya bilangan Reynolds maka koefisien perpindahan kalornya meningkat pula. Hal ini karena aliran yang terjadi semakin terbulen sehingga mempercepat proses pertukaran panas antara fluida 
dingin dengan fluida panas. Bilangan Reynolds 2000, koefisien perpindahan kalornya $21,090 \mathrm{~W} / \mathrm{m}^{2} \mathrm{~K}$ dan bilangan Reynolds 10000, koefisien perpindahan kalornya $37,794 \mathrm{~W} / \mathrm{m}^{2} \mathrm{~K}$.

3. Kapasitas kondensat yang meningkat maka daya pompanya meningkat pula, karena kenaikan daya pompa diperlukan untuk menaikkan laju aliran massa yang akan mempercepat pertukaran kalor. Kapasitas kondensat yang diperoleh $1,481.10-3 \mathrm{~kg} / \mathrm{s}$, $1,879.10-3 \mathrm{~kg} / \mathrm{s}, 2,042.10-3 \mathrm{~kg} / \mathrm{s}$, $2,457.10-3 \mathrm{~kg} / \mathrm{s}$ dan $2,617.10-3 \mathrm{~kg} / \mathrm{s}$ sedangkan daya pompanya $0,129 \mathrm{~W}, 0,256$ $\mathrm{W}, 0,401 \mathrm{~W}, 0,597 \mathrm{~W}$, dan 0,836 W.
4. Semakin tinggi temperaturmasuk fluida dingin maka kapasitas kondensat semakin menurun. Kemampuan air menyerap kalor adalah perkalian kalor jenis dan selisih temperatur sesuai laju aliran massa. Propertis air dalam hal ini kalor jenis $(\mathrm{Cp})$ nilainya menurun dengan meningkatnya temperatur. Namun demikian untuk Bilangan Reynold pada aliran turbulen, pengaruh perubahan temperatur masuk fluida dingin tidak signifikan.

\section{PERSANTUNAN}

Terimakasih kepada Bapak Ir. Subroto, M.T. dan Saudara Agus Purwanto atas kerjasamanya dalam melakukan penelitian ini.

\section{DAFTAR PUSTAKA}

Ardani, M., 2004, Kaji Eksperimental Temperatur Masukan Oli dengan Jarak Sekat Terhadap Performa Alat Penukar Kalor Tipe Selongsong dan Tabung, Tugas Akhir no. R39/ Mes/FT/04, Jurusan Teknik Mesin, Universitas Sebelas Maret, Surakarta.

Evanudin, Y., 2004, Kaji Eksperimental Alat Penukar Panas Tipe Selongsong dan Tabung Satu Lintasan dengan Variasi Potongan Sekat Horisontal UntukAliran Searah, Tugas Akhir S1 Teknik Mesin Universitas Sebelas Maret Surakarta.

Handoyo, A. E., 2000, Pengaruh Kecepatan Aliran Terhadap Efektivitas Shell and Tube Heat Exchanger, jurnal Teknik Mesin vol. 2 no. 2 . Okt 2000 : 86-90, Universitas Kristen Petra, Surabaya. http:/puslit.petra.ac.id/journals/mechanical/iptek.htm. Didownload pada: kamis, 20 maret 2008, 23.05 WIB.

Holman, J.P., 1997, Perpindahan Kalor, edisi keenam, Erlangga, Jakarta.

Incropera, F.P., 1996, Foundamental Heat and Transfer, John Wiley and Sons, Canada.

Laksamanahardja., Rusli., Sumangat., dan Hidayat., 2003, Model Penyulingan Minyak Atsiri Skala Kelompok Tani, Balai Besar Pengembangan Alat dan Mesin Pertanian. http:// library.usu.ac.id/download/fp/tekper-sentosa.pdf. Didownload pada: minggu, 30 september 2007, 12.21 WIB.

Sukirno, 2004, Kaji eksperimen Pengaruh Panjang Terhadap Performa Alat Penukar Kalor Pipa Konsentrik Aliran Sejajar dan Berlawanan Arah, Tugas Akhir no. R38/Mes/FT/ 04, Jurusan Teknik Mesin, Universitas Sebelas Maret, Surakarta. 